\title{
Contribution to the knowledge of Atrichobrunettia Satchel, 1953 (Diptera, Psychodidae) from Brazil
}

\author{
Maíra Xavier Araújo ${ }^{1,2}$ \& Freddy Bravo ${ }^{1,3}$ \\ 1 Univ. Est. de Feira de Santana (UEFS), Depto. de Ciências Biológicas (DCBI0), Lab. de Sistemática de Insetos (LASIS). Feira de Santana, BA, Brasil. \\ ${ }^{2}$ ORCID: http://orcid.org/0000-0003-2447-9901.E-mail:mah.biology@gmail.com \\ 3 ORCID: http://orcid.org/0000-0003-0959-0767. E-mail: freddybra@gmail.com
}

\begin{abstract}
A new species of moth-fly, Atrichobrunettia (Polibrunettia) longipalpis sp. nov. (Psychodinae, Psychodidae), from the Brazilian Atlantic Rain Forest is described. It can be distinguished from other species of the subgenus mainly by the length of palpus that is longer and by the dentate distal margin of hypandrium. Here the distribution of A. angelae Bravo, 2006 and A. paranaensis Bravo, 2005 is reviewed and morphological data to A. paranaensis Bravo, 2006 is given to complement the original description of the species.
\end{abstract}

Keywords. Brunettiini; Polibrunettia; Neotropical; Taxonomy; Atlantic Rain Forest.

\section{INTRODUCTION}

The genus Atrichobrunettia Satchell, 1953 (Psychodidae, Psychodinae) comprises 46 species distributed throughout the world and included in six subgenera, excepting two Neotropical species (Bravo, 2007; Ibáñez-Bernal, 2009). In the Neotropics were described 15 species, there were 15 described species, of which 13 are found in Brazil, one in Costa Rica and one in Mexico (Quate, 1996; Bravo, 2006, 2007; Ibáñez-Bernal, 2009). The subgenera Polibrunettia Bravo, 2006 (Atrichobrunettia bistria (Quate, 1996); A. ampla Bravo, 2006; A. amazonensis Bravo, 2006; A. paranaensis Bravo, 2006; A. spinata Bravo, 2006; A. angelae Bravo, 2006; A. longipenis Bravo, 2006; A. brevicornis Bravo, 2006; A. bispinata Bravo, 2006; and A. xalapaensis IbáñezBernal, 2009) and Pachybrunettia Bravo, 2007 (Atrichobrunettia minuta Bravo, 2006; A. triangularis Bravo, 2007; and A. trilobata Bravo, 2007) were proposed for the Neotropics (Bravo, 2006, 2007). The species Atrichobrunettia bora (Bravo, 2001) and A. pennata Bravo, 2006 were not assigned to any subgenera (Bravo, 2001, 2006).

The present work aims to increase the current knowledge of Atrichobrunettia with the description of a new species, new morphological data to A. paranaensis Bravo, 2006; and new records to A. angelae Bravo, 2006 and A. paranaensis.

\section{MATERIAL AND METHODS}

The studied specimens will be deposited in the Entomological Collection Prof. Johann Becker of the Museu de Zoologia da Universidade Estadual de Feira de Santana, Bahia, Brazil (MZFS). The specimens were treated with $10 \%$ potassium hydroxide $(\mathrm{KOH})$ for approximately three hours, neutralized in acetic acid $20 \%$ for 10 minutes, dehydrated in ethanol, diaphanized in clove oil and mounted in Canada balsam on slides. The general morphology follows Cumming \& Wood (2017). All drawings were made with the aid of a camera lucida and digitally processed using Inkscape 0.48 software. Measurements are given in millimeter $(\mathrm{mm})$.

\section{TAXONOMY}

Class Insecta Linnaeus, 1758

Order Diptera Linnaeus, 1758

Family Psychodidae Newman, 1834

Subfamily Psychodinae Newman, 1834

Genus Atrichobrunettia Satchell, 1953

Atrichobrunettia (Polibrunettia) longipalpis sp. nov.

(Figs. 1A-H)

Diagnosis: Palpus long (palpus formula = 1.0: 5.2: 4.4: 5.2); medial fork basal to radial fork; hypandrium wide with dentate distal margin; parameres subtriangular with pointed and divergent apex.

Male description: Head (Fig. 1A): vertex rounded with setae alveoli regularly spaced and little separated medially; eye-bridge narrow, composed of three rows of facets and separated by approximately four facet diameters; interocular suture complete, inverted U-shaped; frontal scar patch 
of alveoli divided medially; clypeus scar patch of alveoli subquadrangular, undivided. Antenna with scape cylindrical, 1.4 times the length of pedicel; pedicel spherical; flagellum with 14 nodiform flagellomeres, decreasing in size from base to apex, 2-10 strongly eccentric flagel- lomeres; $14^{\text {th }}$ flagellomere with small apiculus (Fig. 1B); a pair of S-shaped ascoids in the flagellomeres 1-13 (Fig. 1C); Palpus formula 1.0: 5.2: 4.4: 5.2. Mouthparts extending beyond basal segment of palpus; labellum with apicolateral bristles (Fig. 1A). Wing with pointed apex; Sc

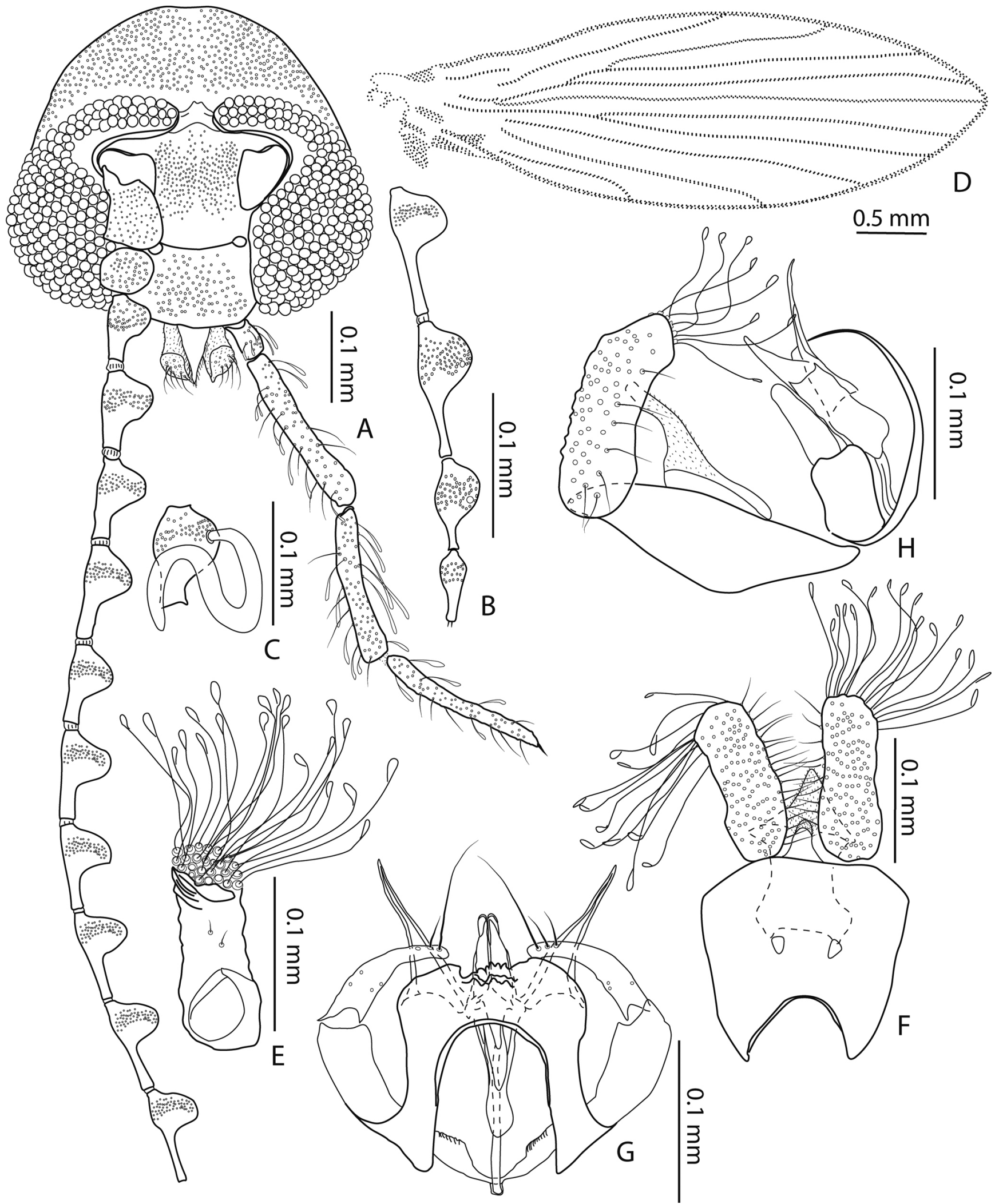

Figures 1. (A-H) Atrichobrunettia longipalpis Araújo \& Bravo, sp. nov. (A) Head. (B) Last four flagellomeres. (C) First flagellomere with ascoid. (D) Wing. (E) Cercus, dorsal view. (F) Epandrium and cerci, ventral view. (G) Hypandrium, gonocoxites, gonostyli, parameres, aedeagus and ejaculatory apodeme, dorsal view. (H) Male terminalia, lateral view: Epandrium, cerci, hypandrium, gonocoxites, gonostyli, parameres, aedeagus and ejaculatory apodeme. 
short and not sclerotized; Rs pectinate, radial fork apical to medial fork; $R_{5}$ ending at the wing tip; $\mathrm{CuA}_{2}$ ending apical to the level of medial fork (Fig. 1D).

Male Terminalia: Cercus cylindrical longer than the length of epandrium; internal surface of cercus with two short bristles; apex with at least 20 long tenacula with rounded tips (Figs. 1E, F, H). Epandrium bare, subrectangular, wider than long, proximal margin concave in ventral view and with two foramina near proximal margin (Fig. 1F). Gonocoxite bare, cylindrical, the same length as gonostylus; gonocoxal apodemes fused, forming a bridge and in contact with proximal portion of ejaculatory apodeme; ejaculatory apodeme narrow and short.
Gonostylus tapered and curved with three bristles at apex, distal one longer than other two. Hypandrium wide, with irregular, dentate and little sclerotized area in the distal margin. Aedeagus with bilobed apex; parameres subtriangular, pointed at apex, sclerotized and divergent, with the same length as gonostylus (Figs. 1G, H).

Female: Unknown.

\section{Material examined}

Holotype: BRAZIL, 1 male; Bahia, Serra da Jibóia, Sede Gambá, 10.v.2017, Silva-Neto, Mendes and Moura leg.; light trap; MZFS.

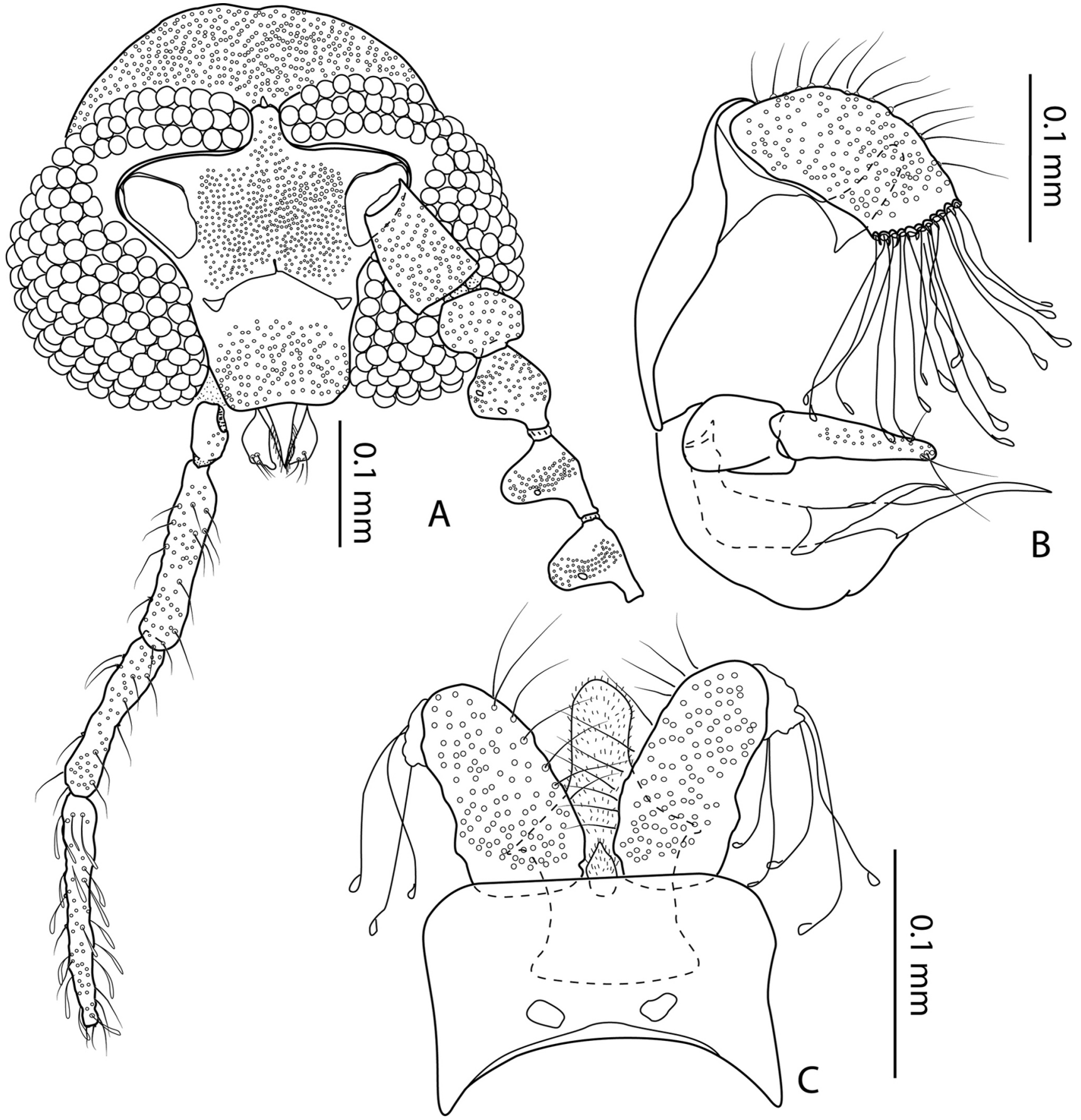

Figures 2. (A-C) Atrichobrunettia paranaensis Bravo, 2006. (A) Head. Male terminalia: (B) Epandrium, cerci, hypandrium, gonocoxites, gonostyli, parameres, aedeagus and ejaculatory apodeme, lateral view. (C) Epandrium and cerci, ventral view. 
Paratypes: BRAZIL: Southeast region: 6 males; São Paulo, Sete Barras, 25.vii-07.viii.2004, without name of collector; Malaise trap; MZFS; 4 males; São Paulo, Sete Barras, 13-27.xi.2004, without name of collector; Malaise trap; MZFS, 3 males; São Paulo, Sete Barras, 24.xii.2004-08.i.2005, without name of collector; Malaise trap; MZFS, 1 male; São Paulo, Sete Barras, 16-30.x.2004, without name of collector; Malaise trap; MZFS. Northeast region: 1 male; Bahia, Serra da Jibóia, Sede Gambá, 10.v.2017, Silva-Neto, Mendes and Moura leg.; light trap; MZFS.

Distribution: Brazil (states of Bahia and São Paulo).

Etymology: The name longipalpis refers to the length of the elongated palpus.

Comments: Based on the key to males of Neotropical species of Atrichobrunettia of Bravo (2006), the new species is included in the subgenus Polibrunettia by following characters: eye bridge separated, narrow; scape $1.0 x-2.0 x$ the length of the pedicel; $R_{5}$ ending at the apex of the wing; apodemes fused forming a gonocoxal bridge; post-hypandrial wide and plate without alveoli; and subtriangular parameres. In addition, the new species is morphologically similar to $A$. longipenis Bravo, 2006 by the length of palpus, little longer in the new species, but differs because the ejaculatory apodeme is wider in A. longipenis; the distal margin of hypandrium dentate in the new species and straight in A. longipenis and by the direction of the parameres, more divergent in $A$. longipenis. The current distribution of the new species included the southeast and northeast of Brazil in the Atlantic Rain Forest of states of São Paulo and Bahia.

\section{Atrichobrunettia (Polibrunettia) paranaensis Bravo} (Figs. 2A-C)

Atrichobrunettia paranaensis Bravo, 2006: 15-17, figs. 14-17.

Male description: Head (Fig. 2A): vertex rounded, with seta alveoli regularly distributed. Eye-bridge narrow, composed of three rows of facets, and separated by 0.5-1.5 facet diameters; interocular suture complete, well sclerotized and inverted U-shaped. Frons with scar patch of alveoli extending to the eyes. Clypeus with a quadrangular patch of alveoli; alveoli more spaced than the alveoli of the frons. Antenna with scape cylindrical, 1.8-2.0 times the length of pedicel; pedicel spherical; flagellomeres nodiform, eccentric. Mouthparts extending little beyond basal segment of palpus; labellum with apicolateral bristles.

Male terminalia (Figs. 2B, C): Cercus subcylindrical with truncated apex; apex with more than 15 long tenacula with rounded tips. Epandrium bare, rectangular, wider than long, proximal margin concave and two foramina near proximal margin. Gonocoxite cylindrical, shortest than aedeagus and triangular gonostylus in lateral view.

\section{Material examined}

Additional material: BRAZIL, 6 males; São Paulo, Sete Barras, 13-27.xi.2004, without name of collector; Malaise trap; MZFS, 1 male; São Paulo, Sete Barras, 24.xii.2004-08.i.2005, without name of collector; Malaise trap; MZFS.

Distribution: Brazil (states of Paraná and São Paulo new record).

Comments: The description of A. paranaensis of Bravo (2006) is complemented with observations made in specimens collected in the State of São Paulo (Sete Barras), which is a new record of the species expanding the northern distribution of the species.

\section{Atrichobrunettia angelae Bravo}

Atrichobrunettia angelae Bravo, 2006: 17-19, figs. 20-23.

Comments: Males of $A$. angelae are recognized by the male terminalia, with the parameres longer than gonocoxite, sclerotinized, triangular and with curved apex. The type specimens were examined and allow the identification of the specimens.

\section{Material examined}

Additional material: BRAZIL, 2 males; São Paulo, Sete Barras, 25.vii-07.viii.2004, without name of collector; Malaise trap; MZFS, 1 male; Bahia, Serra da Jibóia, Sede Gambá, 10.v.2017, Silva-Neto, Mendes e Moura leg.; light trap; MZFS, 1 male; Bahia, Serra da Jibóia, 27.vii.2000, Bravo leg.; MZFS.

Distribution: Brazil, Bahia (Sauípe and Serra da Jibóia new record), Espírito Santo (Santa Maria de Jequitibá), Paraná (Antonina) and São Paulo (Sete Barras - new record).

\section{ACKNOWLEDGMENTS}

The authors would like to thank Gabriel Vieira for the help with some photos of the specimens. The second author received financial support from CNPq (305855/2019-0).

\section{AUTHORS' CONTRIBUTIONS}

M.X.A.: identification and illustration of species, writing original draft; F.B.: identification of species, writing review and editing. Both authors read and approved the final version of the manuscript. 


\section{REFERENCES}

Bravo, F. 2001. Brunettia bora, a new species of moth-fly (Diptera, Psychodidae) from Brazil. Studies on Neotropical Fauna and Environment, 36: 211-214.

Bravo, F. 2006. The taxonomy of Neotropical Brunettina (Diptera, Psychodidae, Psychodiini, Mormiini), with descriptions of ten new species from Brazil and comments on the generic classification of the subtribe. Zootaxa, 1134: 1-28.

Bravo, F. 2007. Descriptions of a new subgenus and two new species of Atrichobrunettia Satchell (Diptera, Psychodidae) from the Neotropical region. Zootaxa, 1590: 61-68.
Cumming, J.M. \& Wood, D.M. 2017. 3. Adult morphology and terminology, pp. 51-63. In: Kirk-Spriggs, A.H. \& Sinclair, B.J. (Eds.). Manual of Afrotropical Diptera. Vol. 1. Introductory chapters and keys to Diptera families. Pretoria, South African National Biodiversity Institute. $1361 \mathrm{p}$.

Ibáñez-Bernal, S. 2009. First record of the genus Atrichobrunettia Satchell in Mexico, with the description of a new species (Diptera, Psychodidae Psychodinae). Zootaxa, 2306: 59-65.

Quate, L.W. 1996. Preliminary taxonomic of Costa Rica: Psychodidae (Diptera), exclusive of Plebotominae. Revista de Biología Tropical, 44: 1-81. 